\title{
A Review of the Research on Asset Allocation Theory
}

\author{
Jianlin Zhao ${ }^{\mathrm{a}}$, Ming Zhou ${ }^{\mathrm{b}}$ \\ Central University of Finance and Economics, Beijing 100081, China \\ azhaojianlin@aliyun.com, bzhouming@cufe.edu.cn
}

Keywords: asset allocation; mean-variance; CAPM; risk parity; black-litterman.

\begin{abstract}
Effective asset allocation is considered the key to successful investment. The research on the theory of asset allocation began in the 1930s. The traditional configuration strategies included $60 / 40$ combination, equal weight combination and mean-variance model. In the 1990s, in order to relax the hypothesis of the strategy, the feasibility of the theory in practice was put forward. A series of asset-based asset allocation strategy based on the GEYR model was proposed. In 21st century, the global economic volatility strengthened, in order to effectively control the risk, to maximize the diversified portfolio, risk-based asset allocation strategy to become the focus of investor attention, risk parity model is one of the typical representatives. At the same time, in addition to the application of quantitative models, investors have begun to pay attention to the impact of the economic cycle, policy cycle and management capabilities, with proud performance of the University Endowment Fund and the operability of the Merrill Lynch clock model to become investors and Use the object.
\end{abstract}

\section{Introduction}

For a long time, effective asset allocation is seen as the key to successful investment. This idea originated in [1], this paper used the performance decomposition method to measure the contribution of investment policies (asset allocation) and investment strategies (securities selection and market timing) to investment income, and pointed out that the asset allocation policy explained income contribution of $93.6 \%$ of the 91 common fund.

Although the importance of asset allocation to investment performance in the end is still far from conclusion, it does not affect its theoretical risk diversification performance. For a variety of asset portfolios, the process of diversifying investment is a major asset allocation process. If the scope of asset allocation from domestic to international, you can diversify risk while achieving higher returns, to achieve the effective expansion of investors outside the border[2-3], which is the essence of international portfolio theory.

In order to strengthen the effective management of large class assets, the United States is the first to focus on large class asset allocation strategy research. In the 1930s, the classic portfolio on the market was to invest $60 \%$ of the total assets in domestic bonds and $40 \%$ to invest in domestic stocks. In the 1950s and 1960s, representative portfolios accounted for about $10 \%$ of cash and equivalents in addition to stocks and bonds. In the mid-to-late 1980s, the market began to invest part of its funds in venture capital, real estate, private equity, overseas markets and emerging market equities and bonds, driven by a number of active investors. By the 1990s and the new century, investors use absolute revenue strategies to incorporate financial derivatives into their investments. With the asset classes become more abundant, the large-scale asset allocation strategy from the 60/40 portfolio, equal weight portfolio, global market portfolio and other traditional configuration strategy to the development of revenue-based and risk-based strategy, and the Merrill Lynch clock model as the representative of the non-quantitative model, large-scale asset allocation theory has experienced from static to dynamic, from qualitative to quantitative, and into the subjective judgment process.

In contrast, China's major asset allocation is still in its infancy. At the practical level, investors make decisions mainly rely on the study of macroeconomic trends to judge, lack of quantitative model support, and thus cannot guarantee the stability of investment decision-making. At the theoretical level, representative research on asset allocation based on Chinese capital market is rare, and due to lag and one-sidedness, existing research cannot be applied to practical operation. Taking into account 
the shortcomings of the existing theory and the actual needs of the future market, this paper summarizes the strategy of large-scale asset allocation, with a view to providing scholars and practitioners with a whole framework of asset allocation.

\section{The Exploration of Asset Allocation}

\subsection{The traditional configuration strategies}

Before the 1960s, while many investors were aware of the importance of asset allocation, but only to endorse its decentralized risk function level, the use of the configuration method is generally a simple constant hybrid strategy, that is, to maintain the investment portfolio in the value of the same kind of assets unchanged. When an asset falls relative to other asset prices, the investor buys the asset and, on the other hand, sells it. Compared to the buy-and-hold strategy, the combination of a constant mix strategy has a weak ability to reduce asset protection and to continue value-added. Typical constant hybrid configuration strategies include equally weighted portfolios and 60/40 portfolio strategy.

As investors' attitudes towards assets tend to be rational, constant hybrid asset allocation strategies cannot meet investor demand. The deepening of the financial market and the rapid reading of transaction information provide the basis for the quantitative and model development of asset allocation. In the 1950s, the Markowitz mean-variance model [4] formally raised which promote asset allocation from the practical level to the theoretical level. The model uses the expectation and variance for the first time to describe the benefits and risks of investment, and transform the asset allocation problem into multi-objective optimization problem. This not only marks the birth of modern investment theory, but also become the important evolution of the subsequent large-scale asset allocation theory. In order to obtain the optimal configuration solution, Markowitz proposed a critical line algorithm, using the quadratic programming problem to solve the model. The generation of meanvariance models, the development of computer technology and statistics make a lot of financial data can be used for investment decision-making, asset allocation theory began to from qualitative analysis to quantitative research.

Although the mean-variance model has made significant scientific achievements in asset allocation, there are some limitations in practical application. In the process of continuous improvement of the mean-variance model, the market portfolio is the product of the mean-variance model, which is the most direct and the closest to the market. It directly reflects the importance of the decision-maker's risk dispersion. Sharpe [5], Lintner [6], and Mossin [7] proposed the capital asset pricing model(CAPM) based on the mean-variance model, and pointed out that under certain assumptions, the market portfolio is the optimal combination of all investors. It is recommended that investors in accordance with the risk asset value to configure their asset allocation. The market portfolio does not need to be reconfigured frequently, so the transaction costs are lower compared to equal weight portfolios. However, the actual operation of the market portfolio has some difficulties. Theoretically, the market portfolio should include all the types of assets that can be invested in the world, and these assets are infinitely divided. However, in reality, the both cannot be satisfied. In addition, the actual investment weight of some assets in the market is often difficult to obtain. As a result, most of the anthropological assumptions have been added to the estimates of market portfolios in the existing literature. In order to get the market portfolio of myopia estimates, Brinson distinguish 9 representative of the global assets from 80 kinds of assets, and use of their historical data from 1960 to 1984 to build a market portfolio.

\subsection{Black-Litterman Model}

The Black-Litterman (B-L) [10] model integrates Markowitz's mean-variance optimal theory and Bayesian hybrid estimation method to incorporate the investor's subjective view into the decisionmaking, which not only solves the problem of parameter credibility, but also makes the model result more stable. The idea of B-L model is as follows: Firstly, the market equilibrium rate of each asset is deduced by using Sharp's inverse optimization theory and CAPM. Then, the combination of decision maker's expectation of future rate of return and the corresponding level of view matrix and confidence matrix, and use the Bayesian rule to form new expectation yield and variance parameters. Finally, the 
newly formed expected yield vector and covariance matrix are substituted into the mean-variance model to obtain the optimal assets configuration scheme.

B-L model has been a very good application in the global asset allocation practice, but because the parameter estimation contains the investor's subjective view, so the model of higher quality requirements. After 1992, in order to make the B-L model more suitable for the real market environment, or more in line with the habits of investors, many scholars and many institutions, including Black and Litterman put forward improve opinion from the input parameters and model structure of the B-L model respectively.

\subsection{Risk Parity Model}

The risk parity [8-9] model is an investment strategy that combines portfolio of long-term benefits with risk control. The model's approach to balance the risk exposure of portfolio is derived from the "all-weather" portfolio of the Bridge Water Fund in the 1960s: when the medium-long-term macroeconomic environment is exacerbated or weakened by inflationary pressures, and economic growth is higher or lower than expected State and cannot be predicted, the equivalent of four subportfolio can ensure that regardless of the kind of economic environment, at least one sub-fund performance.

Later, Qian combined this idea with the concept of risk contribution with more mathematical logic, established a mathematical risk-parity model, and used the 1983-2004 US stock and bond data to test this model and found that compare to the 60/40 combination, the risk parity combination of risk contributions has a higher Sharp ratio.

From the overall performance of the market, over the past 20 years, the risk parity funds in the forefront of the industry. Representative AQR risk parity fund since its inception, always balance the risk to stocks, bonds, currencies, commodities and other assets, and the use spreads, momentum and valuation techniques to make tactical adjustment.

\section{Summary}

Although the theory of large-scale asset allocation has been developed abroad for almost a century, but in China, due to the limited time of development of financial markets, large-scale asset allocation theory and practice has just started, the market and academic field pay more attention to timing and stock choice than the choice of asset class. At the same time, there are many practitioners have misunderstanding of large-scale asset allocation, that it is through a variety of macroeconomic cycle turning point grasp, in the global process of asset selection, but did not realize its nature is a overall strategy of relying on the low correlation between different assets to manage long-term risks and benefits is not a simple addition to local strategies.

Asset allocation is the main driver of long-term gains and control risks. As time goes on, the asset allocation strategy will evolve into a series of more complex models, and the question of "what is the best strategy" is never conclusive. Because the characteristics of each strategy are different, the practical market, timing and theme are different.

China's scholars and institutional investors should pay attention to the field of research: First, a deep understanding of the laws of the capital market on the basis of the construction of China's largescale asset market model; the second is to strengthen the system contribution related to assets allocation, and integrate the results of academic and industry to promote our academic level in the field and simultaneous to developed countries, prepare for more open of capital market for the future.

\section{References}

[1]. Brinson G P, Hood L R, Beebower G L. Determinants of portfolio performance [J]. Financial Analysts Journal, 1995, 51(1): 133-138.

[2]. Grubel H G. Internationally diversified portfolios: welfare gains and capital flows [J]. The American Economic Review, 1968, 58(5): 1299-1314.

[3]. Levy H, Sarnat M. International diversification of investment portfolios [J]. The American Economic Review, 1970, 60(4): 668-675. 
[4]. Markowitz H. Portfolio selection [J]. The journal of finance, 1952, 7(1): 77-91.

[5]. Sharpe W F. Capital asset prices: A theory of market equilibrium under conditions of risk [J]. The journal of finance, 1964, 19(3): 425-442.

[6]. Lintner J. Security prices, risk, and maximal gains from diversification [J]. The journal of finance, 1965, 20(4): 587-615.

[7]. Mossin J. Equilibrium in a capital asset market [J]. Econometrica: Journal of the econometric society, 1966: 768-783.

[8]. Qian E. Risk parity portfolios: Efficient portfolios through true diversification [J]. Panagora Asset Management, 2005.

[9]. Qian E E. On the financial interpretation of risk contribution: Risk budgets do add up[J]. 2005.

[10]. Black F, Litterman R. Global portfolio optimization [J]. Financial analyst's journal, 1992, 48(5): 28-43. 